\title{
Características produtivas e morfológicas do capim Tanzânia em diferentes intensidades de pastejo ${ }^{1}$
}

\section{Production and morphological characteristics of Tanzania grass under different grazing heights}

\author{
Rondineli Pavezzi Barbero ${ }^{2 *}$; Marco Aurélio Alves de Freitas Barbosa ${ }^{3}$; Letícia \\ Maria de Castro ${ }^{4}$; Edson Luís de Azambuja Ribeiro3; Ivone Yurika Mizubuti³; \\ Valter Harry Bumbieris Júnior ${ }^{3}$; Leandro das Dores Ferreira da Silva ${ }^{3}$
}

\begin{abstract}
Resumo
O objetivo deste trabalho foi determinar a melhor altura de pastejo do capim Tanzânia, avaliando características produtivas e morfológicas do dossel forrageiro. Este experimento foi conduzido em Cidade Gaúcha, Paraná, onde foi avaliado o acúmulo de forragem e características morfológicas de pastos de capim Tanzânia manejados a 20;40;60 e $80 \mathrm{~cm}$ de desfolha com lotação contínua e taxa de lotação variável por bovinos de corte. A área experimental foi de 12 hectares divididos em piquetes de um hectare cada. Para cada piquete foram alocadas duas gaiolas de exclusão de pastejo para estimativas de acúmulo de forragem, e oito amostras eram colhidas a cada 28 dias durante todo ano de 2010. O delineamento experimental foi inteiramente casualizado. A massa de forragem das estruturas morfológicas apresentou comportamento linear positivo em função das alturas do pasto. A altura de desfolha não influenciou na taxa de acúmulo de forragem para nenhuma das estruturas morfológicas: lâminas foliares verdes; colmos+bainhas e material senescente. Também não foram observadas diferenças quanto à razão folha: colmo. Todas as alturas do pasto, dentro da amplitude estudada, proporcionaram número adequado de folhas verdes por perfilho. Pastos de capim Tanzânia com lotação contínua, manejados entre 40 e $60 \mathrm{~cm}$ proporcionam elevada massa de lâminas foliares, sem ocorrência de elevação da massa de colmos+bainhas ou material senescente. Pastos de capim Tanzânia, manejados entre em 60 e $80 \mathrm{~cm}$ apresentaram bom acúmulo de folhas no outono, possibilitando maiores ofertas de forragens no período seco.
\end{abstract}

Palavras-chave: Colmo, lâmina foliar, material senescente, perfilho

\begin{abstract}
The objective of this study was to determine the best height of the Tanzania grass under grazing, assessing morphological and productive characteristics of the sward. This experiment was conducted in Cidade Gaucha, Parana, where he was rated the accumulation rate and morphological characteristics of Tanzania grass pastures grazed at 20,40,60 and $80 \mathrm{~cm}$ grazing under continuous stocking with variable stocking rate for beef cattle. The experimental area was 12 hectare divided in paddocks of one hectare each. For each paddock were allocated two grazing exclusion cage for estimating herbage
\end{abstract}

\footnotetext{
1 Projeto financiado pelo CNPq, parte da dissertação de mestrado do primeiro autor.

2 M.e em Ciência Animal, Discente de Doutorado em Zootecnia, FCAV/UNESP, Jaboticabal, SP. E-mail: rondinelibarbero@, zootecnista.com.br

3 Profs. Drs. do Dept $^{\circ}$ de Zootecnia, Centro de Ciências Agrárias, Universidade Estadual de Londrina, UEL, Londrina, PR. E-mail: maafbarbosa@uel.br; mizubuti@uel.br; elar@uel.br; jrbumbieris@uel.br; leandro@uel.br

4 Zootecnista, M.e em Ciência Animal, UEL, Londrina, PR. E-mail: leticiacastro@zootecnista.com.br

* Autor para correspondência
} 
accumulation, and eight samples were taken every 28 days throughout the year 2010 . The completely randomized design. The herbage mass of the morphological structures showed a linear positive function of sward heights. The height of defoliation did not influence the rate of herbage accumulation for any of the morphological structures: green leaf, stem + sheaths and senescent material. There were also no differences in leaf: stem ratio. All heights within the range studied provided adequate number of green leaves per tiller. Tanzania grass pastures grazed under continuous stocking between 40 and $60 \mathrm{~cm}$, for providing a good association between accumulation and mass of green leaf blades, and acceptable values of the mass of stem + sheaths and senescent material. Pasture of Tanzania grass under 60 and 80 $\mathrm{cm}$ allow of leaves satisfactory accumulation in the autumn.

Key words: Culm, leaf, senescent material, tiller

\section{Introdução}

Forrageiras tropicais como o Panicum maximum Jacq.cv.Tanzânia(capim Tanzânia)possuiimportante papel na pecuária de corte, pois apresentam elevado potencial de produção (CARGNELUTTI FILHO et al., 2004) e boa qualidade nutricional (CANO et al., 2004), sendo possível alcançar alta produtividade utilizando conhecimentos sobre o comportamento morfofisiológico e produtivo destas plantas, manejando o pastejo.

Estudos têm demonstrado a influência da intensidade e/ou freqüência da desfolha na dinâmica de tecidos e respostas produtivas das plantas forrageiras (HENDRICKSON et al., 2005; CANDIDO et al., 2006; DA SILVA et al., 2009; CUTRIM JÚNIOR et al., 2010), mas ainda são necessários estudos sobre a resposta vegetal sob lotação contínua. $\mathrm{O}$ entendimento das relações das respostas morfofisiológicas da planta forrageira, em relação a altura do dossel, podem tornar este parâmetro uma alternativa viável no manejo do pastejo (DA SILVA; NASCIMENTO JÚNIOR, 2007).

O objetivo deste trabalho foi encontrar a melhor altura de desfolha em pastos do capim Tanzânia sob lotação contínua por bovinos de corte, com taxa de lotação variável, avaliando características morfológicas e produtivas.

\section{Material e Métodos}

O experimento foi realizado no Município de Cidade Gaúcha, Estado do Paraná, Brasil, com 550 $\mathrm{m}$ de altitude, latitude $23^{\circ} 23$ e longitude $52^{\circ} 56$. Segundo classificação de Köppen o clima da região é Cfa (subtropical úmido com verões quentes e chuvosos e invernos secos), os dados climáticos referentes ao período experimental de 2010 constam na Figura 1.

O solo da área experimental é Podzólico Vermelho-Amarelo, considerado de baixa fertilidade natural, típico do arenito Caiuá (BARBOSA; NASCIMENTO JUNIOR; CECATO, 2006). A análise química do solo na profundidade de $20 \mathrm{~cm}$ apresentou os seguintes resultados: $\mathrm{pH}$ em água= 6,03; $\mathrm{Ca}+2=1,74 \mathrm{cmol} / \mathrm{dm} 3 ; \mathrm{Mg}+2=0,52 \mathrm{mmolc} /$ $\mathrm{dm} 3 ; \mathrm{K}+=0,23 \mathrm{mmolc} / \mathrm{dm} 3 ; \mathrm{Na}+=0,00 \mathrm{cmol} / \mathrm{dm} 3$; $\mathrm{P}$ disponível $=2,36 \mathrm{mg} / \mathrm{dm} 3 ; \quad$ CTC efetiva $=2,49$ $\mathrm{cmol} / \mathrm{dm} 3 ;$ e $\mathrm{Al}=0,00 \%$.

A área experimental foi estabelecida com capim Tanzânia na estação chuvosa de 2009, utilizando-se sementes comerciais, e seguindo as recomendações do fornecedor $\left( \pm 10 \mathrm{~kg}\right.$ sementes $\left.\mathrm{ha}^{-1}\right)$. Foram aplicadas quatro toneladas de cama de aviário por hectare, no plantio e $60 \mathrm{~kg} \mathrm{P}_{2} \mathrm{O}_{5} \mathrm{ha}^{-1}$ aplicados com semeadora de plantio direto a $10 \mathrm{~cm}$ de profundidade e $30 \mathrm{~kg} \mathrm{~N} \mathrm{ha}^{-1}$ e $16 \mathrm{~kg} \mathrm{~K}_{2} \mathrm{O}$ ha ${ }^{-1}$ aplicado no início da primavera. 
Figura 1. Precipitação pluviométrica (Pp), temperatura média máxima $\left({ }^{\circ} \mathrm{C}\right.$ Max.) e mínima $\left({ }^{\circ} \mathrm{C}\right.$ mín.), seguidas pelas médias e desvios, no período experimental de 2010, na região experimental no Noroeste do Paraná.

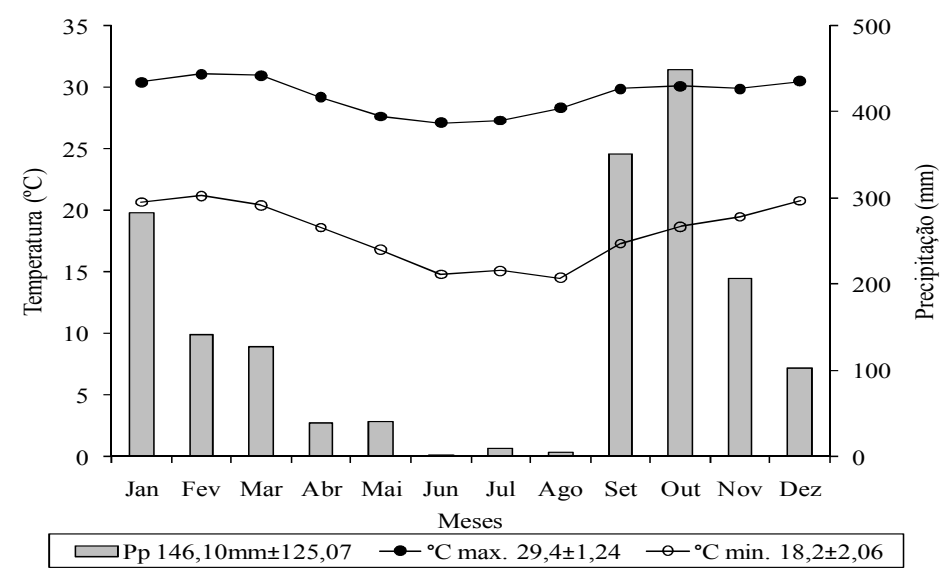

Fonte: Elaborado pelos autores, a partir do acervo de dados SIMEPAR (2012).

A área experimental foi de 12 hectares com relevo levemente ondulado, dividida em 12 piquetes de mesma área, onde foram utilizados três piquetes para cada altura do dossel do capim Tanzânia (20; 40; 60 e $80 \mathrm{~cm})$, distribuídos aleatoriamente. $\mathrm{O}$ período experimental foi entre os meses de janeiro e dezembro de 2010, sendo 30 dias prévios ao início do experimento destinados ao estabelecimento das alturas pretendidas. Para manutenção da altura do dossel foram utilizados três bovinos por piquete, machos da raça Nelore, com peso médio inicial de $340 \mathrm{~kg}$, castrados e vermifugados previamente ao período experimental.

A altura do dossel era mensurada em intervalos de 14 dias em 20 pontos aleatórios por piquete, com régua graduada, na curvatura das lâminas foliares superiores, e conforme a necessidade de ajuste para manutenção das alturas, animais adicionais eram introduzidos ou retirados (MOTT; LUCAS, 1952). As alturas reais do dossel forrageiro no período experimental são representadas na Figura 2.

Para estimativa de massa de forragem, foram colhidas oito amostras com corte ao nível do solo, com quadrado metálico de $0,25 \mathrm{~m}^{2}$ em pontos representativos do dossel, ao final de cada período de 28 dias. Duas gaiolas de exclusão do pastejo foram alocadas por piquete para determinação do acúmulo da forragem, também em períodos de 28 dias, sendo que o acúmulo era obtido pela diferença entre a massa final e inicial de cada período.

As amostras colhidas foram pesadas, identificadas, e conduzidas ao laboratório, para separação das estruturas morfológicas: folhas verdes, material senescente e colmos + bainhas. Para determinação de matéria seca foram seguidos procedimentos descritos por Mizubuti et al. (2009). Foram separados aleatoriamente 20 perfilhos por amostra, dos quais foram contados número de lâminas foliares verdes, senescentes e peso dos perfilhos.

O delineamento experimental foi inteiramente casualizado, com três repetições (piquetes) por tratamento. Após verificação das pressuposições estatísticas, foi aplicada análise de variância, e quando efeitos significativos $(\mathrm{P}<0,05)$ aplicados procedimentos de regressão nas variáveis contínuas, e teste de médias nas variáveis discretas.

\section{Resultados e Discussão}

A massa média de forragem de lâminas foliares verdes; colmos + bainhas e material senescente nas estações, bem como equações que descrevem seu comportamento podem ser observados na Tabela 1. Foi observado comportamento linear positivo em função do aumento da altura do dossel forrageiro para as estruturas morfológicas em todas as estações. 


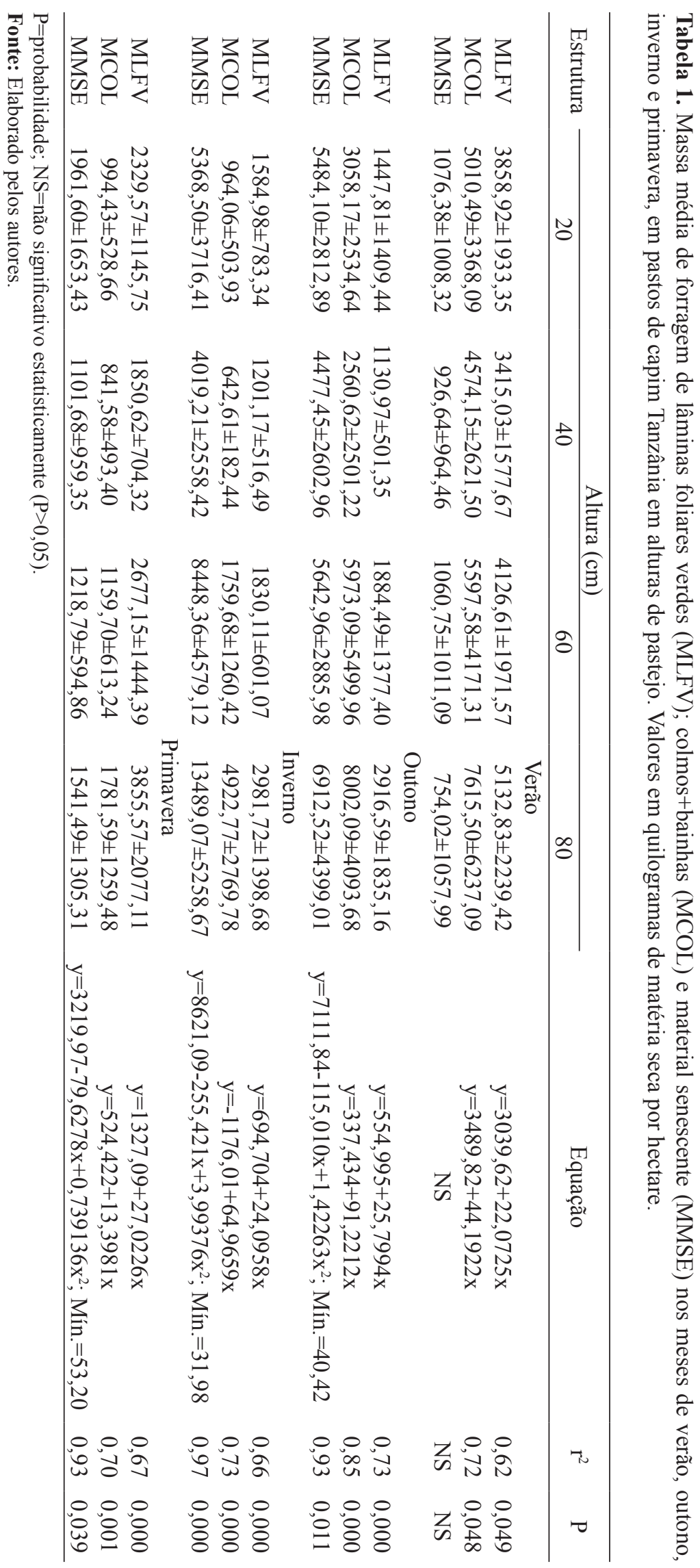


Um fator negativo apresentado foi a maior massa de colmos em relação à massa de lâminas foliares verdes no verão, outono e inverno (exceto em pastos de $20 \mathrm{~cm}$ no inverno), pois se deseja disponibilizar material de melhor valor nutritivo (CANO et al., 2004). Estes efeitos provavelmente foram apresentados devido à altura de entrada dos animais (Figura 2), quando já havia ocorrido o alongamento dos colmos, problema comumente observado em pastos de capim Tanzânia (BARBOSA; NASCIMENTO JUNIOR; CECATO, 2006).

Figura 2. Médias das alturas reais nos meses de 2010 do capim Tanzânia em função das alturas pretendidas, seguidas pelas médias anuais e desvios.

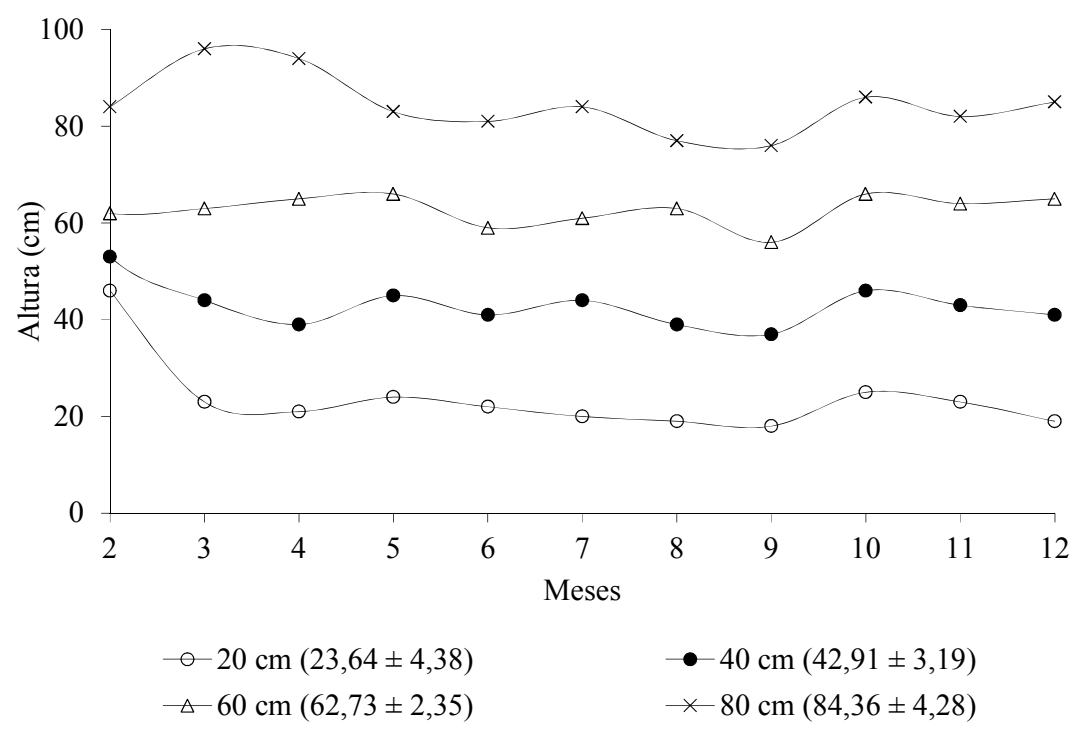

Fonte: Elaborado pelos autores.

Nas estações do outono, inverno e primavera houve comportamento quadrático da massa de material senescente, com pontos de mínima massa observados entre 31,98 e $53,2 \mathrm{~cm}$. Canto et al. (2008) apontaram alturas entre 40 e $60 \mathrm{~cm}$ como ideal para manejo do capim Tanzânia no final da primavera, pois neste intervalo é apresentada boa relação entre as estruturas morfológicas da planta, condizente com os resultados encontrados neste trabalho.

As alturas estudadas não mostraram diferenças quanto à taxa de acúmulo média anual de lâminas foliares verdes $\left(31,94 \pm 32,32 \mathrm{~kg}\right.$ MS ha-1 $\left.\mathrm{dia}^{-1}\right)$; colmos + bainhas $\left(64,95 \pm 40,43 \mathrm{~kg} \mathrm{MS} \mathrm{ha} \mathrm{dia}^{-1}\right)$; material senescente $\left(41,04 \pm 34,11 \mathrm{~kg}\right.$ MS ha- dia $^{-}$ $\left.{ }^{1}\right)$ e razão folha: colmo $(1,51 \pm 1,29)$. Também não houve interações entre alturas e estações.

As condições climáticas da primavera e do verão (Figura 1) proporcionaram melhores condições de desenvolvimento vegetal. Porém, foi observado na altura de $80 \mathrm{~cm}$ acúmulo de lâminas verdes no período do outono similar ao observado na primavera e no verão (Figura 3), sugerindo que esta altura do dossel forrageiro proporcionou teores favoráveis de reservas no final do verão, fazendo com que esta fosse menos prejudicada em relação às demais alturas estudadas. 
Figura 3. Acúmulo total de matéria seca de forragem por hectare de lâminas foliares em pastos de capim Tanzânia em alturas de pastejo 20; 40; 60 e $80 \mathrm{~cm}$ nas estações verão (V); outono (O); inverno (I) e primavera (P). Letras iguais não diferem pelo teste de Tukey $(\mathrm{P}<0,05)$.

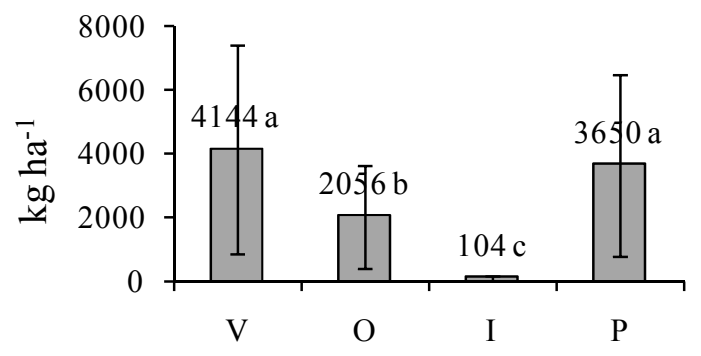

A)

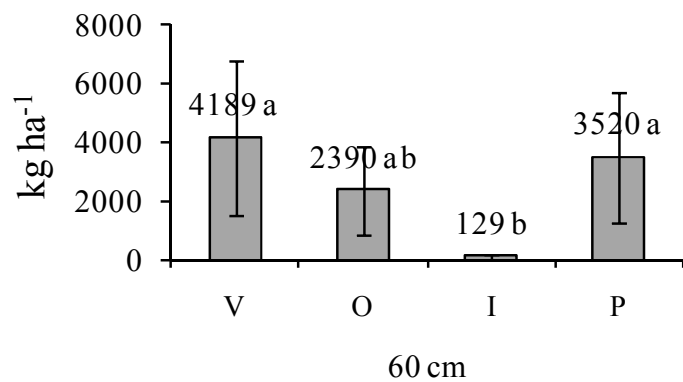

C)

Fonte: Elaborado pelos autores.

O desenvolvimento vegetal é altamente dependente da luminosidade interceptada pelas lâminas foliares (BORGES et al., 2011), desta forma, o alongamento dos colmos é um recurso utilizado pela forrageira na busca por luz em determinadas situações. O maior acúmulo de colmos+bainhas ocorreu na estação da primavera em relação às demais estações (Figura 4), sendo que este resultado é devido ao fato que, no início do período experimental os pastos já haviam apresentado alongamento destas estruturas, evidenciando nestas condições o acúmulo decorrente da recuperação pós-inverno, na estação da primavera.

Nos pastos de maior altura, o acúmulo de material senescente no verão foi resultante do sombreamento dos extratos inferiores do dossel,

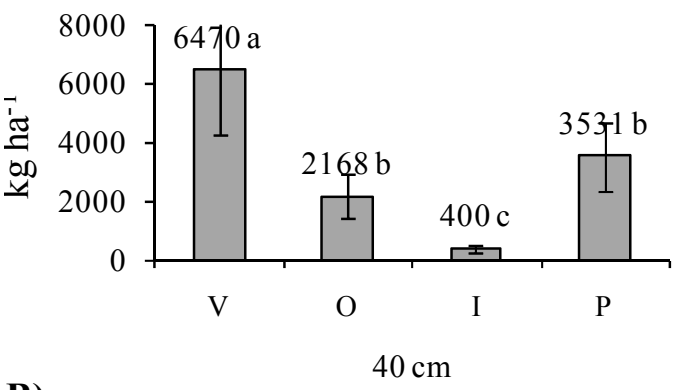

B)

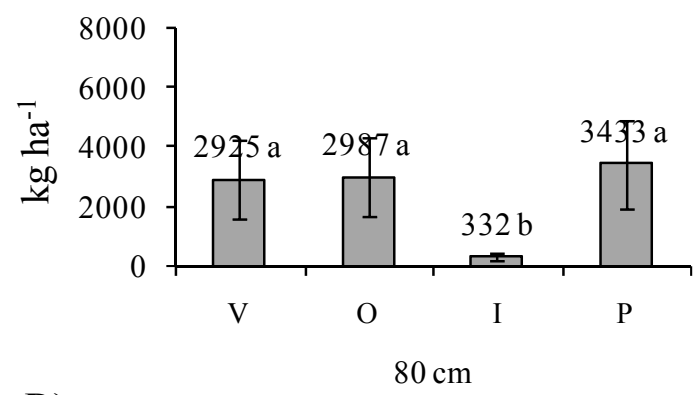

D)

enquanto que nos pastos mais baixos, a senescência foi causada principalmente por pisoteio, devido à elevada taxa de lotação média anual (5,53 U.A. $\left.\mathrm{ha}^{-1}\right)$, necessária para manutenção das alturas préestabelecidas. Os maiores valores para acúmulo de material senescente foram observados no outono e no inverno (Figura 5).

O peso dos perfilhos apresentou aumento linear em função da altura do pasto em todas as estações do ano, exceto no inverno, onde apresentou resposta quadrática (Tabela 2). O mesmo comportamento também foi observado para o número de lâminas foliares verdes por perfilho, exceto na estação de inverno, onde não foi observada diferença entre as alturas de manejo. 
Figura 4. Acúmulo total de massa de matéria seca de forragem por hectare de colmos+bainhas em pastos de capim Tanzânia em alturas de pastejo 20; 40; 60 e $80 \mathrm{~cm}$ nas estações verão (V); outono (O); inverno (I) e primavera (P). Letras iguais não diferem pelo teste de Tukey $(\mathrm{P}<0,05)$.

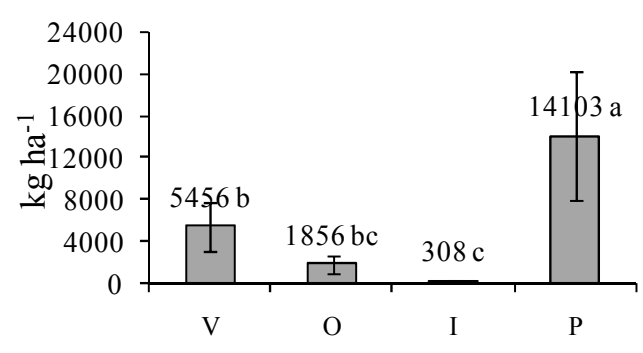

A)

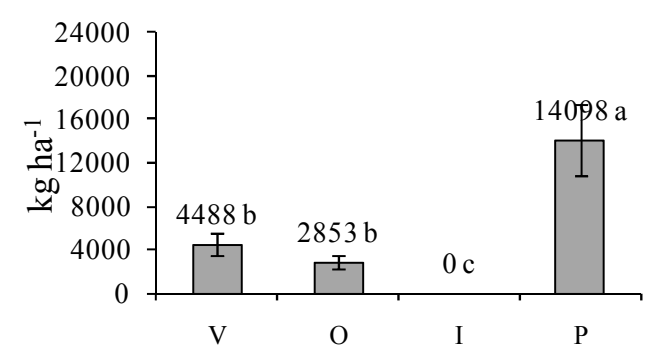

C)

Fonte: Elaborado pelos autores.

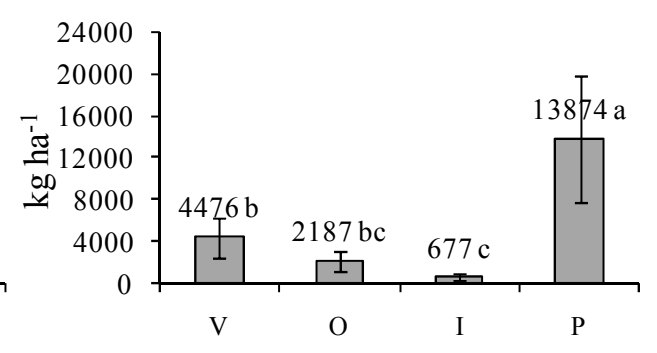

B)

$40 \mathrm{~cm}$

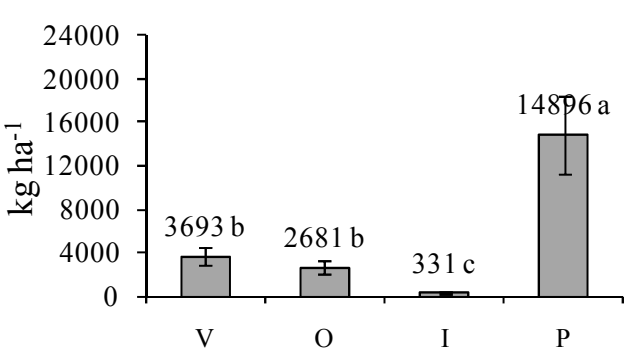

D)

$80 \mathrm{~cm}$

Figura 5. Acúmulo total de massa de matéria seca de forragem por hectare de material senescente em pastos de capim Tanzânia em alturas de pastejo 20; 40; 60 e 80 cm nas estações verão (V); outono (O); inverno (I) e primavera (P). Letras iguais não diferem pelo teste de Tukey $(\mathrm{P}<0,05)$.

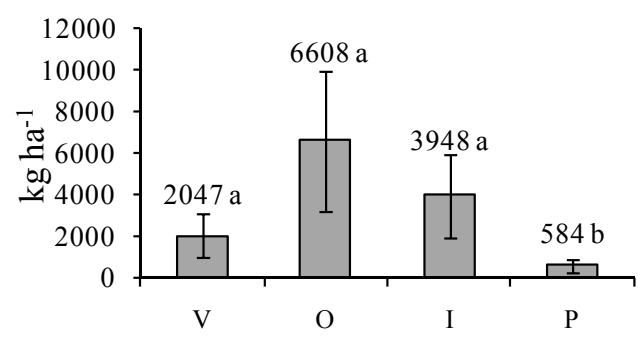

A)

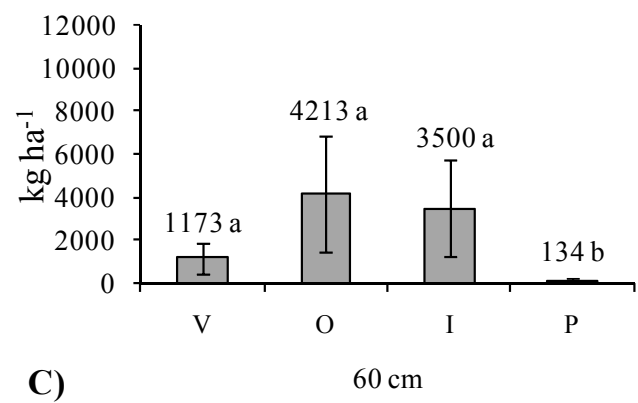

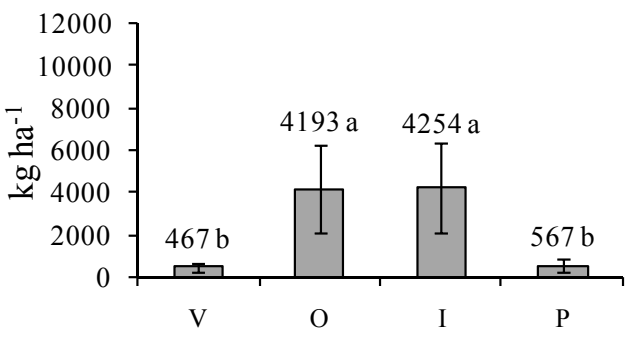

B)

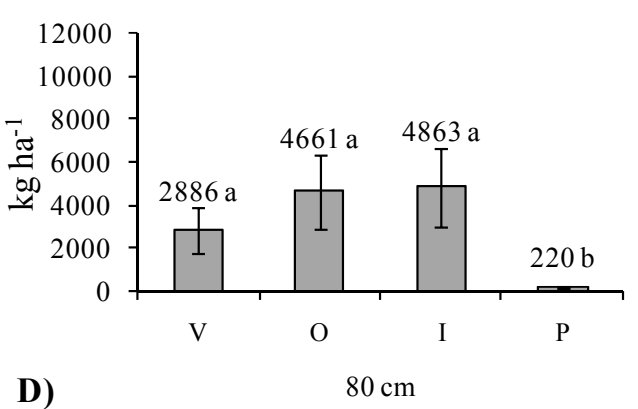

Fonte: Elaborado pelos autores. 
Não houve ocorrência de número de lâminas foliares verdes superior a quatro folhas por perfilho em nenhuma das estações, sendo o maior valor observado de $3,78 \mathrm{em}$ pastos de $80 \mathrm{~cm}$ no verão, o que de acordo com Pena et al. (2009) é favorável ao equilíbrio das estruturas da planta para que não ocorra alongamento excessivo dos colmos. $\mathrm{O}$ número de lâminas senescentes ou mortas por perfilho apresentou comportamento linear crescente somente na estação do outono, sendo que no verão não foi detectada diferença significativa entre as alturas do dossel.

No inverno e na primavera houve comportamento quadrático do número de lâminas foliares senescentes por perfilhos em função das alturas do pastejo, com ponto de máximo número de folhas mortas em 49,47 cm no inverno $\left(\mathrm{R}^{2}=0,99\right)$ e 51,67 $\mathrm{cm}$ na primavera $\left(\mathrm{R}^{2}=0,95\right)$. Aparentemente, nestas estações alturas próximas a $50 \mathrm{~cm}$ possibilitam redução do sombreamento das porções mais basais, e menores senescência.

O peso médio dos perfilhos, número de lâminas foliares verdes e número de lâminas foliares senescentes por perfilho apresentaram comportamento similar em função das diferentes alturas do dossel forrageiro estudadas. $\mathrm{Na}$ estação da primavera foram obtidos os menores números de lâminas foliares mortas ou senescentes para as quatro alturas de pastejo, devido principalmente a fatores climáticos, que condiz com a rebrotação e recuperação da forrageira após o inverno.

Tabela 2. Peso médio de perfilhos (PMPP); número de lâminas verdes (NLVP) e folhas senescentes por perfilho (NLSP), equação de regressão e coeficiente de determinação $\left(\mathrm{r}^{2}\right)$ em pastos de capim Tanzânia nas diferentes estações, pastejados em diferentes alturas.

\begin{tabular}{|c|c|c|c|c|c|c|c|}
\hline & \multicolumn{4}{|c|}{ Altura $(\mathrm{cm})$} & \multirow{2}{*}{ Equação } & \multirow{2}{*}{$\mathrm{r}^{2}$} & \multirow{2}{*}{$\mathrm{P}$} \\
\hline & 20 & 40 & 60 & 80 & & & \\
\hline \multicolumn{8}{|c|}{ Verão } \\
\hline PMPP & $3,66 \pm 2,76$ & $8,55 \pm 6,99$ & $19,12 \pm 10,38$ & $17,20 \pm 10,51$ & $y=-0,629983+0,255624 x$ & 0,82 & 0,000 \\
\hline NLVP & $2,85 \pm 1,09$ & $2,49 \pm 1,29$ & $3,12 \pm 2,09$ & $3,39 \pm 1,58$ & $\mathrm{y}=2,50794+0,0119841 \mathrm{x}$ & 0,57 & 0,032 \\
\hline NLSP & $0,51 \pm 0,80$ & $1,55 \pm 1,71$ & $1,76 \pm 1,65$ & $0,68 \pm 1,07$ & $y=-0,912839+0,0979753 x-0,000948086 x^{2}$ & 0,95 & 0,000 \\
\hline \multicolumn{8}{|c|}{ Outono } \\
\hline PMPP & $6,53 \pm 3,23$ & $4,59 \pm 4,22$ & $9,74 \pm 7,31$ & $18,41 \pm 9,36$ & $y=0,378491+0,203970 x$ & 0,74 & 0,000 \\
\hline NLVP & $2,79 \pm 1,38$ & $2,95 \pm 0,97$ & $3,16 \pm 2,15$ & $3,52 \pm 1,62$ & $y=2,41158+0,0112016 x$ & 0,57 & 0,007 \\
\hline NLSP & $1,03 \pm 1,09$ & $0,65 \pm 1,22$ & $1,09 \pm 1,36$ & $1,71 \pm 1,76$ & $y=0,500000+0,0124603 x$ & 0,56 & 0,001 \\
\hline \multicolumn{8}{|c|}{ Inverno } \\
\hline PMPP & $2,69 \pm 2,06$ & $1,49 \pm 1,07$ & $2,63 \pm 1,77$ & $3,58 \pm 2,20$ & $y=4,35426-0,116274 x+0,00135292 x^{2}$ & 0,85 & 0,000 \\
\hline NLVP & $2,36 \pm 0,76$ & $2,33 \pm 0,56$ & $2,41 \pm 1,18$ & $2,39 \pm 0,61$ & NS & NS & NS \\
\hline NLSP & $0,95 \pm 0,29$ & $0,96 \pm 0,30$ & $0,27 \pm 0,47$ & $0,26 \pm 0,44$ & $y=-0,0172155+0,132150 x-0,00133549 x^{2}$ & 0,99 & 0,024 \\
\hline \multicolumn{8}{|c|}{ Primavera } \\
\hline PMPP & $5,09 \pm 3,32$ & $6,57 \pm 6,15$ & $14,43 \pm 10,10$ & $17,81 \pm 9,23$ & $y=2,77009+0,225328 x$ & 0,94 & 0,000 \\
\hline NLVP & $2,82 \pm 1,23$ & $2,72 \pm 1,16$ & $3,14 \pm 2,42$ & $3,46 \pm 1,59$ & $\mathrm{y}=2,45000+0,0166250 \mathrm{x}$ & 0,80 & 0,000 \\
\hline NLSP & $0,77 \pm 0,98$ & $1,10 \pm 1,55$ & $1,43 \pm 1,49$ & $1,19 \pm 1,54$ & $y=-0,912839+0,979753 x-0,000948086 x^{2}$ & 0,95 & 0,004 \\
\hline
\end{tabular}

$\mathrm{P}=$ probabilidade; $\mathrm{NS}=$ não significativo estatisticamente $(\mathrm{P}>0,05)$.

Fonte: Elaborado pelos autores 


\section{Conclusões}

O intervalo de alturas estudadas não influenciou o número de lâminas foliares verdes por perfilho. Pastos de capim Tanzânia com lotação contínua por bovinos de corte, manejados entre 40 e 60 $\mathrm{cm}$ apresentam elevada massa de lâminas foliares verdes, com valores relativamente baixos de massa de material senescente. O manejo do capim Tanzânia com alturas entre 60 e $80 \mathrm{~cm}$ proporcionaram acúmulo de lâminas foliares verdes no outono, sendo indicadas quando o objetivo é o uso dos pastos no período seco.

\section{Referências}

BARBOSA, M. A. A. F.; NASCIMENTO JUNIOR, D.; CECATO, U. Dinâmica da pastagem e desempenho de novilhos em pastagem de capim-tanzânia sob diferentes ofertas de forragem. Revista Brasileira de Zootecnia, Viçosa, MG, v. 35, n. 4, p. 1594-1600, 2006.

BORGES, B. M. M. N.; SILVA JÚNIOR, L. C.; LUCAS, F. T.; SILVA, W. J. Relação entre o fluxo luminoso interceptado em diferentes épocas no índice de área foliar de diferentes forrageiras. Semina: Ciências Agrárias, Lodnrina, v. 32, n. 4, p. 1589-1594, 2011.

CANDIDO, M. J. D.; SILVA, R. G.; NEIVA, J. M.; FACÓ, O.; BENEVIDES, Y. I.; FARIAS, S. F. Fluxo de biomassa em capim-tanzânia pastejado por ovinos sob três períodos de descanso. Revista Brasileira de Zootecnia, Viçosa, MG, v. 35, n. 6, p. 2234-2242, 2006.

CANO, C. C. P.; CECATO, U.; CANTO, M. W.; SANTOS, G. T.; GALBEIRO, S.; MARTINS, E. N.; MIRA, R. T. Valor nutritivo do capim-Tanzânia (Panicum maximum Jacq. cv. Tanzânia-1) pastejado em diferentes alturas. Revista Brasileira de Zootecnia, Viçosa, MG, v. 33, n. 6, p. 1959-1969, 2004.

CANTO, M. W.; JOBIM, C. C.; GASPARINO, E.; HOESCHL, A. R. Características do pasto e acúmulo de forragem em capim-tanzânia submetido a alturas de manejo do pasto. Pesquisa Agropecuária Brasileira, Brasília, v. 43, n. 3, p. 429-435, 2008.
CARGNELUTTI FILHO, A.; CASTILHOS, Z. M. S.; STORCK, L.; SAVIAN, J. F. Análise de repetibilidade de caracteres forrageiros de genótipos de Panicum maximum, avaliados com e sem restrição solar. Ciência Rural, Santa Maria, v. 34, n. 3, p. 723-729, 2004.

CUTRIM JÚNIOR, J. A. A.; CANDIDO, M. J. D.; VALENTE, B. S. M.; CARNEIRO, M. S. S.; CARNEIRO, H. A. V.; CIDRÃO, P. M. L. Fluxo de biomassa em capim-tanzânia sob três freqüências de desfolhação e dois resíduos pós-pastejo. Revista Brasileira de Saúde e Produção Animal, Salvador, v. 11, n. 3, p. 618-629, 2010.

DA SILVA, S. C.; BUENO, A. A. O.; CARNEVALLI, R. A.; UEBELE, M. C.; BUENO, F. O.; HODGSON, J.; MATTHEW, C.; ARNOLD, G. C.; MORAIS, J. P. G. Sward structural characteristics and herbage accumulation of Panicum maximum cv. Mombaça subjected to rotational stocking managements. Scientia Agricola, Piracicaba, v. 66, n. 1, p. 8-19, 2009.

DA SILVA, S. C.; NASCIMENTO JÚNIOR, D. Avanços na pesquisa com plantas forrageiras tropicais em pastagens: características morfofisiológicas e manejo do pastejo. Revista Brasileira de Zootecnia, Viçosa, MG, v. 36, p. 122-138, 2007.

HENDRICKSON, J. R.; BERDHAL, M. A.; LEIBIG, A.; KARN, J. F. Tiller persistence of eight intermediate wheatgrass entries grazed at three morphological stages. Agronomy Journal, Madison, v. 97, n. 5, p. 1390-1395, 2005.

MIZUBUTI, I. Y.; PINTO, A. P.; PEREIRA, E. S.; RAMOS, B. M. O. Métodos laboratoriais de avaliação de alimentos para animais. Londrina: EDUEL, v. 1, 2009. $228 \mathrm{p}$.

MOTT, G. O.; LUCAS, H. L. The design conduct and interpretation of grazing trials on cultivated and improved pastures. In: INTERNATIONAL GRASSLAND CONGRESS, 6., 1952, Pensylvania. Anais... Pensylvania State College: [s. n], 1952. p. 1380-1395.

PENA, K. S.; NASCIMENTO JUNIOR, D.; SILVA, S. C.; EUCLIDES, V. B. P.; ZANINE, A. M. Características morfogênicas, estruturais e acúmulo de forragem do capim tanzânia submetido a duas alturas e três intervalos de corte. Revista Brasileira de Zootecnia, Viçosa, MG, v. 38, n. 11, p. 2127-2136, 2009. 
